\title{
The Role of Leadership Competencies in Supporting the Al Nahda University for Becoming a Learning Organization: A New Qualitative Framework of the DLOQ
}

\author{
Said Sayed Shabban Abdo Sayed ${ }^{1} \&$ David Edgar $^{2}$ \\ ${ }^{1}$ School of Marketing and Management, AL Nahda University (NUB), New Bani Sweif City, Egypt \\ ${ }^{2}$ Strategy \& Business Transformation, Department of Business Management, Glasgow School for Business and \\ Society, Glasgow Caledonian University, Glasgow, Scotland, United Kingdom \\ Correspondence: David Edgar, Professor, Strategy \& Business Transformation, Department of Business Management, \\ Glasgow School for Business and Society, Glasgow Caledonian University, Cowcaddens Road, Glasgow, G4 0BA, \\ Scotland, United Kingdom.
}

Received: January 21, 2019

Accepted: February 6, 2019

Online Published: February 20, 2019

doi:10.5430/ijba.v10n2p43

URL: https://doi.org/10.5430/ijba.v10n2p43

\begin{abstract}
Purpose: The purpose of this study is to contribute to research on learning organizations in higher education institutions (HEIs), by researching the role of individual, group, and organization competencies and skills that support the (NUB) Al Nahda University in Egypt toward becoming a learning organization.

Design/methodology/approach: Semi-structured interviews were conducted with eight executive academics and researchers in (NUB) Al Nahda University in Egypt. Questions emphasised leadership competencies, including those at individual, group, and organizational level, for utilising their skills in creating, sharing and transferring knowledge for modifying and changing their behaviour to achieve a learning organization.

Findings: Leadership competencies emerged as a complementary component to the DLOQ framework and it was found that the Seven Characteristics (7Cs) proposed by Watkins and Marsick (2003) did not lead to being a learning organization, nor did being a learning organization lead to knowledge performance and financial performance by itself unless fully supported by leadership competencies, as was confirmed in the case of the Al-Nahda University operating in Egypt.

Originality/value: There is still a lack of investigation and global response to the question of how leadership competencies can support learning inside higher education institutions. The outcomes of this research allow a better understanding of how leadership competencies can support the process of becoming a learning organization in HEIs, via a qualitative investigation of the DLOQ framework.
\end{abstract}

Keywords: higher education institutions (HEI), universities, DLOQ, learning organization, leadership competencies

\section{Introduction}

The changeable environment of the world economy has triggered huge challenges in management. Managerial skills and becoming a learning organization are essential to contest such challenges. (Afshari et al., 2013) Over the years, the task of universities has transformed and academies throughout the world are progressively being pushed to change, for instance by decreased state funding, increased availability of online technology, shifting demographics, globalization, and the recruitment of students from different backgrounds and with different professional experience (Voolaid and Ehrlich, 2017). Thus capable leaders will be required with the skills needed to face these changes (Shafiei and Fard, 2015).

Universities can acquire substantial benefits from the practice of learning organization concepts. Higher institutions leaders and scholars can adopt organizational learning ideas to evaluate the external environment, assess organizational competencies, and apply approaches to boost institutional efficiency.

Many consider that the learning organization is the best work atmosphere, where "people continually expand their capacity to create the results they truly desire, where new and expansive patterns of thinking are nurtured, where collective aspiration is set free, and where people are continually learning to see the whole together" (Senge 2006, p. 3). However, although activities of institutions of higher education are intrinsically connected to learning, for 
instance innovation, research, teaching and supervision, these do not constitute the circumstances needed for universities to be regarded as learning organisations (Portfelt, 2006). To truly become learning organizations, universities have to change through constructing a learning environment. This is brought about by improving leadership and the structural and cultural capability to learn, and by creating knowledge and knowledge management. Staff are encouraged to learn only if their leaders reflect these behaviours and the culture and mechanisms needed for learning are established (Prelipcean and Bejinaru, 2016).

The driver of this study is the aim to contribute to knowledge by determining which competencies of its academics can enable the Nahda (NUB) University in Egypt to become a learning organization. More precisely, this research seeks to create insights into the competencies and skills that encourage the creation, acquisition, and transfer of knowledge that can modify organizational behaviour and turn organizational change into a learning process, in this context.

\section{Literature Review}

In their work, The Dance of Change, Senge et al. (2014, p. 21) quote a statement by a manager in the Shell Company that, "we understand that the only competitive advantage the company of the future will have is its managers' ability to learn faster than their competitors". Similarly, Mababu and Revilla (2016, p.2) assert that "The capacity to learn is essential for organizations in order to develop innovative products and services, to be more competitive and to build upon and deliver value to stakeholders". In a learning organization, individuals frequently create, acquire, and transfer knowledge, helping their firm acclimatize to the changeable environment faster than its competitors (Garvin, 2008), thus their individual capacities in these areas underpin the process of becoming a learning organization. Indeed, leaders have the opportunity to respond in a different way to environmental challenges in the same situations (Dobák and Antal, 2010). Since leaders are frontrunners of change in organizations, they can efficiently practise conceptual skill to increase the learning abilities of the organization. These abilities include strategic and smart visions and thinking (Shafiei and Fard, 2015). Leadership competencies have been defined as "the combination of knowledge, skills, traits, and attributes that collectively enable someone to perform a given job" (Zenger and Folkman, 2002, p. 83). In addition, Voolaid and Ehrlich (2017) emphasise the importance of the role of leadership in the development of "the universities as learning organizations" (ibid. p.361). Accordingly, it is claimed that the utilization of executives' and leaders' skills can change an educational organization into learning organization (Afshari et. al 2013). However, although learning in higher education institutions depends upon the ability of leaders and academics to maintain a flow of knowledge across the structural boundaries of the university (Dee and Leišyte, 2017), the question of how competencies and abilities could support learning inside higher education institutions is yet to be explored (Ferincz, 2016).

To enhance knowledge sharing and collective problem solving, universities embrace learning and possessing knowledge as key principles, and allocate committees and other team-based structures for these purposes (Borden and Kezar, 2012). Nevertheless, Dee and Leišytė (2017) argue that a number of structural and cultural features of universities and institutions of higher education can constrain the process of becoming a learning organization, for example:

1. High levels of specialization and structural differentiation, cultural values and reward systems that promote individual accomplishment and weak feedback regarding performance and outcomes (Kezar and Elrod, 2012)

2. Extensive decentralization and traditions of autonomy for academic units and faculties can result in units operating as distinct silos, with little interaction, coordination or learning among them (Dee and Leišyte, 2017).

Research on universities as learning organizations is rare (Strandli Portfelt, 2006; Voolaid and Ehrlich, 2017). Moreover, there is evidence to suggest that universities might, in effect, make little effort to nurture internal knowledge flows (Dee and Leišyte, 2017).

But what are the skills that required supporting the process of learning organization in terms of creating, acquiring, and transferring knowledge, and modifying its behaviour for turning organizational change into a learning process as defined by Garvin (2008)?

The debates in the current literature concerning HEIs as learning organizations (Patterson, 1999; Willcoxson, 2001; Voolaid and Ehrlich, 2017) have been mainly theoretical, though supported by some empirical research, Their characterizations of the learning organization at universities include "university culture and structure, learning climate, learning partner model, interdisciplinary cooperation, the role of leaders and teamwork" (Voolaid and Ehrlich, 2017) but to the best of the present knowledge, no previous study has investigated the skills that support 
academics and researchers in the learning organization process so as to achieve the kind of learning organization proposed by Garvin et al. (2008).

Thus, the aim of this study is to understand the role of individual skills in terms of the ability to create, acquire, and transfer knowledge for modifying organizational behaviour to reflect new knowledge and insights in order to overcome the barriers to the process of becoming a learning organization in the Nahda (NUB) University in Egypt.

\section{Research Questions}

The current research questions are based on a quantitative method, and have been qualitatively rephrased and reformulated according to the Dimensions of the Learning Organization Questionnaire (DLOQ) framework, as recommended by Kim et al. (2015, p. 107).

To meet the above overarching aim, the questions to be answered were as follows:

1. What are the skills that support academics in the Nahda (NUB) University in Egypt to create, acquire and transfer knowledge among colleagues, employees and departments? Are there any types of conflicts, interests or barriers that can modify their behaviour to reflect new knowledge and insights, and how can these barriers to the learning organization process be overcome? (The role of skills in supporting learning)

2. To what extent are academics supported in learning and developing skills and encouraged to express their own views? (Individual level)

3. In what ways does the Nahda (NUB) University in Egypt foster group autonomy, collaboration, motivation, and self-reflection? (Group level)

4. To what extent does the Nahda (NUB) University in Egypt enable free and open communication, exchange of ideas, invest in learning within employees and the academic community? How does it evaluate their ability to meet goals and improve employees' skills and capacities? (Organization level)

5. To what extent do academics give moral leadership and act as motivators and enablers of learning within the organisation for achieving the optimal financial performance? (Organizational performance)

\section{Conceptual Framework}

In the literature, there is a comprehensive agreement that the evaluation process in empirical research needs to be grounded on theoretical bases (DeVellis, 2003).

Researchers have attempted to identify and evaluate the characteristics that define learning organizations. The Dimensions of the Learning Organization Questionnaire (DLOQ) framework, is a well-known multidimensional framework developed by Watkins and Marsick (2003). It comprises seven dimensions, comprising leadership for learning, system connection, embedded system, continuous learning, dialogue and inquiry, empowerment, and team learning (Kim et al., 2015)

According to Ortenblad, (2002) the DLOQ framework incorporates four predominant elements, namely workplace learning, learning climate, organizational learning, and learning structure view. In addition, the DLOQ enables scholars to investigate predictors of the learning organization concept (Mahseredjian, Karkoulian, and Messarra, 2011).

The DLOQ was selected as a framework for this research as it has been internationally tested and utilised broadly in learning organizational studies (Kim, Egan and Tolson, 2015), including those by Watkins and Dirani (2013) and Kim, Watkins and Lu (2016) (as cited in Watkins and Kim, 2018, p.19). It provides a structured questionnaire that is in line with Senge's theory of the learning organization (Voolaid and Ehrlich, 2017).

Watkins and Marsick's DLOQ model of learning organization highlights three key constituents:

a) Systems-level, continuous learning, leading to;

b) Creation and managing of consequent knowledge, which leads to;

c) Enhancement in the organization's performance, and ultimately its value, as assessed via financial resources and non-financial intellectual capital (Jyothibabu and Farooq, 2010)

Voolaid and Ehrlich, (2017) analysed various definitions of the learning organization throughout the current literature (Senge, 1990; Nonaka, 1991; Pedler et al., 1991; Garvin, 1993; Watkins and Marsick, 1993; Örtenblad, 2002) and found that , a consensus that the proposed seven dimensions of the DLOQ model by Watkins and Marsick learning organization are all considered as criteria for learning organization assessment. The model incorporates two key organizational components- people and structure- and identifies seven different but interconnected characteristics of 
a learning organization as illustrated in Tables 1 and 2.

Table 1. Seven dimensions of a learning organization

\begin{tabular}{|c|c|c|c|}
\hline No. & Level & Dimension & Description \\
\hline 1 & Individual & $\begin{array}{l}\text { Create continuous learning } \\
\text { opportunities }\end{array}$ & $\begin{array}{l}\text { Continuous opportunities are provided for people to learn on the } \\
\text { job. }\end{array}$ \\
\hline 2 & Individual & $\begin{array}{l}\text { Promote inquiry and } \\
\text { dialogue }\end{array}$ & $\begin{array}{l}\text { The culture supports people's sharing of views, questions, } \\
\text { feedback and experimentation. }\end{array}$ \\
\hline 3 & Team & $\begin{array}{l}\text { Encourage collaboration } \\
\text { and team learning }\end{array}$ & $\begin{array}{l}\text { People are expected to learn and work together; collaboration is } \\
\text { valued and } \\
\text { Rewarded. }\end{array}$ \\
\hline 4 & $\begin{array}{l}\text { Organizatio } \\
\text { nal }\end{array}$ & $\begin{array}{l}\text { Create systems to capture } \\
\text { and share learning }\end{array}$ & $\begin{array}{l}\text { Technology allows people to share learning and is integrated with } \\
\text { work. }\end{array}$ \\
\hline 5 & $\begin{array}{l}\text { Organizatio } \\
\text { nal }\end{array}$ & $\begin{array}{l}\text { Empower people toward a } \\
\text { collective } \\
\text { vision }\end{array}$ & $\begin{array}{l}\text { The organization shares a collective vision with its members; } \\
\text { people participate in developing and implementing the vision. }\end{array}$ \\
\hline 6 & $\begin{array}{l}\text { Organizatio } \\
\text { nal }\end{array}$ & $\begin{array}{l}\text { Connect the organization } \\
\text { to its environment }\end{array}$ & $\begin{array}{l}\text { The organization is connected to its internal and external } \\
\text { environments; people see and respond to these connections in } \\
\text { their work. }\end{array}$ \\
\hline 7 & $\begin{array}{l}\text { Organizatio } \\
\text { nal }\end{array}$ & $\begin{array}{l}\text { Provide strategic } \\
\text { leadership for learning }\end{array}$ & $\begin{array}{l}\text { Leaders model and support learning; strategic leadership is used } \\
\text { to move the business forward. }\end{array}$ \\
\hline
\end{tabular}

Source: Marsick and Watkins (2003: p.139).

Table 2. Key results

\begin{tabular}{|c|c|}
\hline Key results & Definitions \\
\hline Financial performance & State of financial health and resources available for growth \\
\hline Knowledge performance & $\begin{array}{l}\text { Enhancement of products and services because of learning and knowledge capacity } \\
\text { (lead indicators of intellectual } \\
\text { capital) }\end{array}$ \\
\hline
\end{tabular}

Source: Marsick and Watkins (2003: p.139).

Watkins and Marsick's seven dimensions, as illustrated in Table 1, fall into individual, group or organizational levels of learning and system areas. It has a number of unique features. For instance, it has a clear and comprehensive delineation of the concept of the learning organization. It delineates the concept from an organizational culture perspective and hence offers sufficient measurement domains for constructing a scale (Jyothibabu and Farooq, 2010). Moreover, the model not only categorizes key dimensions of the learning organization but also incorporates them by specifying their relationships (Birdthistle, 2006).

Although the DLOQ has become ubiquitous and has been further developed, numerous statistical drawbacks have been identified regarding its construct validity, and the researchers' analyses have resulted in incoherent factor structures (Kim et al. 2015). Nevertheless, it is still regarded as "the preferred choice among available instruments for learning organization researchers" (Watkins and Kim, 2018, p.21)

However, the previous studies did not offer strategic alternatives on how to evaluate the effectiveness of learning organizations by incorporating Watkins and Marsick's seven dimensions as individual skills and capabilities that aid in creating, acquiring, and transferring knowledge for modifying managers', academics' and employees' behaviour to reflect new knowledge and insights to overcome barriers to the learning organization process and to achieve optimal performance.

Moreover, previous studies used the DLOQ in measuring the degree to which an institution was a learning organization but did not include the interview technique to further investigate the learning process of the organization and only approached the research from a quantitative standpoint. Furthermore, although the critical roles of individual capabilities and skills in the learning organization process have been emphasised (Watkins and Marsick 2003), nevertheless, previous research did not consider the role of Marsick's seven dimensions qualitatively, in a case 
study, through the lens of managerial skills acting in supporting the process of learning organization for achieving optimal performance in Higher Education institutions. Holyoke et al. (2012) recommended employing, qualitative methodology "to better understand applications of the concepts in the context of higher education and to delve deeper into cultural barriers that these institutions face as they attempt to adapt to continuous change" (ibid. p.11).

Therefore, the researcher preferred to use DLOQ model of Watkins and Marsick (1993) to frame the seven dimensions in terms of individual's skills and abilities that may support the learning process in the Nahda (NUB) University in Egypt.

\section{Methodology}

\subsection{Research Context}

The Al Nahda HEI includes six faculties: Pharmacy; Oral and Dental Medicine; Engineering; Computer Science, Mass Communication, and Marketing \& Business Administration. Al-Nahda University (NUB) is located in Upper Egypt. It was established in 2006 and is a private University run by Thebes Education (https://en.wikipedia.org/wiki/Nahda_University).

\subsection{Research Approach}

Interviews were conducted with eight participants who held strategic executive positions in Al-Nahda University (NUB) to gain understandings regarding the competencies and skills that support knowledge creation, sharing and transfer to modify behaviour of learning organization. For that reason, qualitative research via semi-structured interviews with an interpretivist stance was utilised, based on Watkins and Marsick's advice that: "individuals, at most levels can take the DLOQ itself, but often, only middle- and higher-level managers are comfortable answering the performance questions" (Watkins and Marsick, 2003, p.138). Therefore, eight face-to-face interviews were conducted through scheduled appointments with executives, researchers, and senior academics, including deans of faculties, senior academics and researchers (Table 3). Before each interview, the researcher handed each candidate information regarding the research terminology and concepts to facilitate dialogue in the interview. Consent to record each interview was obtained formally from the. interviewees who were guaranteed that their provided information and identification would be kept privileged. Candidates were allowed to decline to answer any questions or to withdraw from the interview at their convenience.

Table 3. The eight interviews conducted in the Al Nahda University (NUB) in Egypt

\begin{tabular}{|c|c|c|c|c|c|c|c|c|c|}
\hline No. & Name & Gender & Nationality & Job Title & Industry & Location & $\begin{array}{l}\text { Interview } \\
\text { Duration } \\
\text { in minutes }\end{array}$ & Profile & Additional Skills \\
\hline 1 & A G & Female & Egyptian & $\begin{array}{l}\text { Senior } \\
\text { lecturer }\end{array}$ & $\begin{array}{l}\text { Higher } \\
\text { Education }\end{array}$ & Cairo & 50 & $\begin{array}{l}13 \text { years of experience } \\
\text { in } \mathrm{HE}\end{array}$ & English /Romanian \\
\hline 2 & N S & Female & Egyptian & $\begin{array}{l}\text { Senior } \\
\text { lecturer }\end{array}$ & $\begin{array}{l}\text { Higher } \\
\text { Education }\end{array}$ & Cairo & 45 & $\begin{array}{l}18 \text { years of experience } \\
\text { in } \mathrm{HE}\end{array}$ & English/French/ Arabic \\
\hline 3 & A M & Male & Egyptian & Dean & $\begin{array}{l}\text { Higher } \\
\text { Education }\end{array}$ & Cairo & 50 & $\begin{array}{l}26 \text { years of experience } \\
\text { in } \mathrm{HE}\end{array}$ & $\begin{array}{l}\text { English/ } \\
\text { accountant/ } \\
\text { Trainer }\end{array}$ \\
\hline 4 & $\mathrm{AH}$ & Male & Egyptian & Dean & $\begin{array}{l}\text { Higher } \\
\text { Education }\end{array}$ & Cairo & 45 & $\begin{array}{l}30 \text { years of experience } \\
\text { in } \mathrm{HE}\end{array}$ & $\begin{array}{l}\text { English } \\
\text { consultant }\end{array}$ \\
\hline 5 & A A & Male & Egyptian & Dean & $\begin{array}{l}\text { Higher } \\
\text { Education }\end{array}$ & Cairo & 45 & $\begin{array}{l}28 \text { years of experience } \\
\text { in } \mathrm{HE}\end{array}$ & $\begin{array}{l}\text { English/ Formal } \\
\text { representative of the Ministry } \\
\text { of Higher education in Egypt }\end{array}$ \\
\hline 6 & E A & Female & Egyptian & $\begin{array}{l}\text { Researche } \\
\mathrm{r}\end{array}$ & $\begin{array}{l}\text { Higher } \\
\text { Education }\end{array}$ & Cairo & 40 & $\begin{array}{l}8 \text { years of experience } \\
\text { in } \mathrm{HE}\end{array}$ & English \\
\hline 7 & E S & Female & Egyptian & $\begin{array}{l}\text { Researche } \\
\mathrm{r}\end{array}$ & $\begin{array}{l}\text { Higher } \\
\text { Education }\end{array}$ & Cairo & 40 & $\begin{array}{l}10 \text { years of experience } \\
\text { in Higher Education }\end{array}$ & English/ Financial consultant \\
\hline 8 & F R & Female & Egyptian & $\begin{array}{l}\text { Associate } \\
\text { Lecturer }\end{array}$ & $\begin{array}{l}\text { Higher } \\
\text { Education }\end{array}$ & Cairo & 56 & $\begin{array}{l}12 \text { years of experience } \\
\text { in } \mathrm{HE}\end{array}$ & English/ German \\
\hline
\end{tabular}

The eight interviews each took between 40 to 60 minutes and were transcribed into Microsoft Word documents. The 
transcripts were revised, summary notes were made and analysed by a thematic analysis method with an inductive approach. (Miles and Huberman, 1994)

\section{Analysis of Findings}

\subsection{Leadership for Creating a Continuous Learning Climate}

It has been argued by Marsick and Watkins (2003) that in order to support continuous learning, organizations are required to build a learning climate and culture. Once they learn by experience, leaders construct these cultures influencing the learning of others, and transferring strong opportunities and success. Örtenblad (2018, p.4) sees the organization as a facilitator, where "creating a climate for learning implies that the organization offers tools and opportunities for learning to the individuals and groups within it. The employees are encouraged to experiment, and "failure" is regarded as a learning opportunity".

The subsequent excerpts from the interviews illustrate how the academics and researchers of the Al Nahda University in Egypt believed they were trying to support continuous learning by creating a climate for learning individuals, groups, and the organization by allowing students to learn by informal learning opportunities, on-the-job learning, and learning by experience. The interviewees explained how, as organizational leaders, they supported students to learn from each other through master-class events, removed structural obstacles and obtained feedback to expand learning and share their vision.

"We do visits to the well-known TV channels, journals and newspapers, and invite famous actors, authors as guest speakers so as to transfer their knowledge and experience in the field of mass communications to our staff and students. We are increasing the allocated funds for research; also, we are trying reduce the tuition fees for our school as it is a theoretical one, so as to attract more students from different backgrounds." (AA)

"Even in terms of students' exam schedule, we are seeking to get their feedback on it to accommodate their time, interests and desires. This kind of independence allows students and their instructors to have a sense of creativity without any kind of university structure to impede their learning." (HM)

"We have an outreach system so as students can teach their colleagues by providing tuition, guidance and consultancy to their assignments, presentations, and study projects, etc. They help overseas students from Nigeria, Niger, Asia in learning our culture as well; thus at the end of the day we learn from each other." (NS)

The above excerpts confirm the conclusions of other researchers that organizational academics and researchers as leaders are pursuing a climate for continuous learning by allowing flexibility, flat organizational structure and a flow of knowledge among students, their colleagues and peers. These results confirm the findings of Gentle and Clifton (2017) that the learning climate and structure comprise the cornerstone to develop the connections needed for building learning organizations. Specifically, the HEIs improve the learning climate via action learning which develops a shared vision.

The findings of the interviews also corroborate the views of Prelipcean and Bejinaru (2016) that academies and HEIs that emphasise teaching and learning cannot be entitled as learning organisations unless they build a learning climate, creating knowledge and knowledge management. Creating a constructive learning climate includes improving the leaderships' capacity to learn, enhancing the structural and cultural capability and learning tools. Thus, leaders exhibit such behaviour to instigate members to learn. Thus, the main fundamentals that support learning in the HEIs are developing building leadership capacity, nurturing instructor and learner's autonomy, continuous development, raising creativity (Chrispen and Mukeredz, 2013, Mababu and Revilla, 2016).

\subsection{Managing Resources for Promoting Inquiry and Dialogue}

An additional common competence among the interviewees was that managing resources was defined by them as being open-minded to innovative thoughts and having the ability to perform in a way that will support effectiveness in leadership. Managing resources is identified by Müller and Turner (2010) as "one of the exceptional leadership characteristics" (ibid., p.22) and can be considered as one of the essential competences of a learning organization and has been described as establishing clear objectives, planning, bring together all resources and coordinating them efficiently and effectively, observing and assessing team's work regularly and giving truthful feedback (Duelwicz and Higgs, 2005, p. 111).

"I sent the faculty members, students and staff to practical and empirical visits to the stock market, factories, banks, financial organizations so as to get knowledge and information from real experience, get in touch with the CEOs and senior managers of these organizations. When they come back, we ask them to give simulation case studies in a presentation in format in front of their colleagues so as to transfer this acquired experience and information for 
stimulating discussion, brainstorming and feedback, to benefit them to come up with creative ideas, and knowledge." (AM)

"As a faculty of pharmacy, we have an annual conference exclusively for our students to present their research results, conclusions, recommendations for further research openly, so as these can be transferred to their peers, colleagues and supervisors to make use of this information in terms of new drugs, formulas, innovations, etc. These actions help in reshaping the attendees' mindset, way of research, and study to benefit themselves and community." (HM)

"We do incessant meetings and workshops with instructors, teaching assistants, and staff to know the current situation of the NUB, problems that were raised, proposed ways and methods for solving them; we always encourage our brainstorming for coming up with new ideas and opinions. At the end of these meeting the NUB publicises the meeting and its outcomes on the NUB homepage in the news tube. It is a creative way of learning by and from each other and broadcasting such process to the world." (NS)

The respondents of the interviews confirmed that their ability to manage resources as a leadership competence enabled them to be open-minded, support new ideas and innovation through dialogue by sending their students for on-the-job learning outside the university, instructors and peers, and also to receive a positive feedback on these endeavours without suffering any kind of criticism. Allowing this behaviour helped to establish dialogue and discussion to generate innovative ideas. The findings of this research confirm the findings of other empirical studies. For instance, Mababu and Revilla (2016, p. 2431) concluded that: "Inquiry involves questioning that simultaneously challenges assumptions and yet does not attack the individual; so, promoting Inquiry and Dialogue refers to effective dialogue that calls for open minds and open communication in the organization."

Learners in private HEIs frequently form individual and solid connections with instructors, which increase and enhance their communication, dialogue and learning. It has been argued that skills that establish a robust relationship between leaders and subordinates through dialogue and discussion have a positive impact on learning organization (Alavi and Liedner, 2001) However, these findings contradict the claims in the literature that "Although higher education institutions have missions that promote learning, ironically, these organizations seldom use learning as a means to improve the institution as a whole" (Dee and Leišyte, 2017.p. 281)

Moreover, Senge (1999) argues that 'learning leaders' should discuss guiding ideas, and then inspire others via those ideas. Consequently, learning activities like questioning the status quo, giving and receiving feedback, and promoting dialogue, allow people to "gain productive reasoning skills to express their views and the capacity to listen and inquire into the views of others" (Watkins and Marsick, 1996, p. 139).

Thus, the role of managing resources as a leadership competence in supporting the process of becoming a learning organization can be seen in the practical evidence in the above excerpts.

\subsection{Engaging in Communication to Encourage Collaboration and Team Learning}

Another competence of leaders which emerged as critical in a learning organisation environment is engaging in communication.

Engaging in communication, has emerged as a catalyst of project success (Gido and Clements 1999, Müller and Turner, 2006) and involves the "availability for communication, setting the stage for mutual exchange ... encouraging exchange by listening and evaluating information from different perspectives and then combining it with their own opinion and discussing these with joint objective, finding the right level of communication detail, meaning finding the right amount and type of information to communicate to for a given audience.' (Müller and Turner, 2011, p. 24)

This was echoed in the words of the participants, who stated through the interviews that their competence in engaging in communication enabled them to encourage dialogue and collaboration with their students, colleagues and other universities in the world to support knowledge sharing, promote knowledge though conversation and dialogue at individual, group and organizational levels. This competence facilitated the learning process, experimentation and the application of the learning ideas with collaboration and team work in learning practices, as shown in these excerpts from the transcripts:

"We also encourage collaborations with external institutes from all over the world to exchange information, research and sometimes we modify some research outcomes to fit with our culture in terms of media and mass communication." (AA)

"We encourage collaboration and team working via open dialogue, discussions and teaching assistant's who've completed his or her Masters or PhD, present their research journey and findings through open seminar as a 
condition before obtaining their degrees; this helps in turn for creating knowledge, transferring this knowledge to the attendees, including students, lecturers, professors, etc., allowing the attendees to acquire this knowledge and in the meanwhile getting feedbacks, modifications, corrections on their result to be addressed in their research. I have also created a central building for research, so you can find students, colleagues, and staff from the faculty of oral and dental medicine collaborating with our faculty of pharmacy, using our equipment and devices, recourse to us for clarifications regarding their research, and we benefit as well from them, and all of us benefit the society.' (H M)

'Currently we have the dynamic system approach in our university; for instance, I have an SMEs (Small Medium Enterprise) centre to collaborate with colleagues, instructors, and students to provide guidance, consultancy, and afford marketing tuition to projects for students and researchers of the faculty of engineering and for pharmaceutical products for those of the faculty of pharmacy, and product research, for those of faculty of oral and dental medicine.' (AM)

In line with these excerpts, respondents generally stated that competence in engaging communication facilitated their learning process, which corroborated the conclusions and recommendations of other empirical studies. For example: "A lively and enthusiastic communicator engages others and wins support. Clearly communicates instructions and vision to staff. Communications are tailored to the audience's interests and focused. Communication style inspires staff and audiences, conveys approachability and accessibility' (Dulewicz and Higgs, 2005, p.111)

Encouraging collaboration and team learning among interviewees from Al Nahda University was based on their ability and communicative skills in holding seminars, workshops, and conferences to utilise knowledge sharing, challenge researcher's ideas and give feedback to help them to modify and correct their research outcomes. Such practices were also identified in other empirical research. For example, Beso et al. (2008) concluded that dialogue promotion and open communication require: "Recognizing in front of the rest of the team their own lack of knowledge about different topics, or about how some tasks must be done. Favouring the exchange of different opinions and points of view that can lead to better team decisions. And when a team thinks it can learn a lot from the different team members, then team work is stimulated as a way of learning from each other" (ibid., p. 150). Similarly, "team learning is enhanced when teams learn the skills of framing, reframing, experimenting, crossing boundaries, and creating an integrative perspective" (Mababu and Revilla, 2016, p. 243).

Thus, via meetings and seminars, and supported by the communicative competence of executive academics, collaborative team learning can occur, and researchers apply their learning in practice and enable the Al Nahda University to become a learning organization.

\subsection{Strategic Perspective for Creating Systems to Capture and Share Learning}

"Strategic perspective relates the project manager's ability to see the bigger picture and evaluate the impact of change, risks and stakeholders on decisions and tasks in projects" (Müller and Turner, 2010, p.32). According to the findings of Dulewicz and Higgs (2005), "managers scoring higher on dimensions relevant to strategic perspective competency generally tend to be more extraverted and emotionally well-adjusted, and specifically to have greater strategic perspective and conscientiousness" (ibid., p.4).

The interviewees confirmed that their strategic perspective, as an intellectual competency, enabled them to perceive the daily activities of their faculties in a wider perspective, so as to capture and share learning by the aid of the ELS, as a technological tool to send and receive messages and work to and from students, to monitor attendance and absenteeism of students and colleagues, to review students' and researchers' work and provide feedback, so as to allow knowledge and information to be spread. Moreover, all these will be stored as a knowledge archive and repository over time to benefit both new and old staff.

The findings of this theme corroborate those of other empirical studies that a strategic perspective involves "building organizational capacity for new thinking that is then embedded and shared with others. Organizations should preserve what is learned and how it is learned, so that it will endure even with a highly mobile, temporary workforce" (Mababu and Revilla, 2016, p.2431)

As well as the ELS, interviewees mentioned that other technological tools, such as the NUB Facebook page, WhatsApp, and email also helped them to capture, utilise and share knowledge among students and colleagues. The subsequent excerpts corroborate Watkins and Marsick's definition of how organisations create systems to capture and share learning: "Both high- and low-technology systems to share learning are created and integrated with work; access is provided; systems are maintained" (Watkins and Marsick, 2003, p.139).

"In knowledge acquisition and sharing, we are relying on our ELS (Electronic Learning System) portal. Both colleagues and students can transfer their request to me and also to each other by our Facebook page, WhatsApp, 
email, and ELS portal; we have a tap called suggestions, so anyone can transfer his/her views/ opinions, comments, interests to us for my input, these activities will be available over long periods for old and new staff." (AA)

"We can also discuss via the ELS any problem or conflict that may arise though uploading videos with some issues and questions that required answers, such as case study schedule, assignment deadline, exam marks distribution etc. and our students send back to us their works for our reviews that we provide them to correct and amend their work. Thus, we create, transfer, acquire knowledge and make it useful to our students in a holistic approach to be accessible as knowledge archive." (NS)

"I am very proud that we are working in an environment of paperless learning. Via the ELS, wherever I have been, I immediately can share my information in terms of the daily tasks, affairs, comments and scheduled minutes to my staff and colleagues. In addition, I can also track and monitor the attendance and absence of the staff and students digitally and be aware of every single matter running there and based on that I can take my decision and plan of action." (AM)

"Of course all of the faculty activities have to be under my supervision, monitoring as I'm tracking and monitoring students and staff commitments via their submitted fingerprints in terms of their attendance and absence, their research deadlines, lab projects schedule, uploading materials for students on time, etc." (HM)

The analysis of the above transcripts, regarding the strategic perspective competency of academics and researchers at the NUB corroborates the findings of Dulewicz and Higgs (2005) and their conclusions that a leader with strategic Perspective competency: "Sees the wider issues and broader implications. Explores wide range of relationships, balances short- and long-term considerations. Sensitive to the impact of one's actions and decisions across the organisation. Identifies opportunities and threats. Sensitive to stakeholders' needs and the implications of external factors on decisions and actions. (ibid., p.7)

According to the interviewees, academics and researchers in the NUB utilised both high- and low-technology systems to share learning and created and integrated knowledge with their colleagues and students, as well as storing and archiving it for further accessibility. This is in line with the findings by other scholars that in "IT-projects, a strategic perspective is seen as a good thing if the project manager can see the bigger picture and is sensitive to the stakeholders' needs" (Müller and Turner, 2010, p. 33). Watkins and Marsick (2003) point out that "What is learned is what the organization retains, such as a new capacity, a new understanding of what does not work, or a new procedure or technology" (ibid., p. 4). Similarly, Ramjeawon and Rowley (2017) argue the benefits of "HEIs with good IT infrastructure, which provides opportunities for communication and networking, and access to resources". (ibid., p.375)

According Senge (1990), being a learning organization permits the organization to holistically assimilate knowledge, sees individuals and the business as a living system, and allows for communication between these parts. Thus, Thus lack of strategic perspective competency was considered as detrimental for a for learning organization in the case of the (NUB) for creating systems to capture and share learning on individual, group, and organizational level.

\subsection{Developing for Empowering People Toward a Collective Vision}

Developing is another critical competency that aids empowering people toward a collective vision, according to the findings of this research and is one of the five managerial competences which relates to basic leadership behaviour (Müller and Turner 2010, p.21). Developing has been identified in the literature by many authors, for instance by Slater and Narver (1995), who concluded that great leaders develop individuals and nurture the development of a robust leadership channel in the organisation.

Developing leaders has been termed by Senge (1990) as regarding leaders as 'teachers', stressing the significance of coaching, facilitating those around them to reorganise their view of reality and being able to solve problems with innovative methods.

Dulewicz and Higgs (2005) describe someone with Developing competency as a leader who 'Believes others have potential to take on ever more-demanding tasks and roles, encourages them to do so. Ensures direct reports have adequate support. Develops their competencies and invests time and effort in coaching them so they contribute effectively and develop themselves. Identifies new tasks and roles to develop others. Believes that critical feedback and challenge are important. (ibid., p.111)

The academics and researchers interviewed emphasised the significance of Developing as a critical competency in enabling them to develop students and colleagues and equip them with the relevant knowledge, skills and capabilities, as can be inferred from the subsequent excerpts. 
'Students and their parents are not alone; we help students financially to contribute with more and more research, we alleviate studying abroad burdens by providing motivational scholarships for those who obtain grade A first year subjects to keep on progressing.' (HM)

'We are aiming to encourage and improve our students' critical thinking and creative thinking, problem solving skills; I gave the case study for instance, or annual report to do interpretations of the weakness and strength points or SWOT analysis that leads to judgement or recommendations at the end of his/ her mind-set. Thus we are arming the student with professional, academic, and leadership skills for the future.' (AM)

'The new president of the NUB is aiming to increase the salaries of the staff to engage exclusively in the learning process, do international research, also increase the allocated budget for research, allocating additional scholarships for students with distinctions grade, increase the allocation of funds for traveling for attending conferences, seminars, and for presenting international papers research.' (AG)

'For instance, I'm teaching the HR module which is based on continuous learning to my students in terms of instructing them presentation skills, CV building, the body language, as tacit knowledge, and therefore, I promote their confidence on how to sell themselves as competent candidates in the competitive market.'(FR)

A number of informative instances were given by interviewees regarding how, as leaders, the executives academics and researchers of the NUB motivated and encouraged their students and colleagues to undertake additional research endeavours, allocating additional funds for granting them overseas scholarships, arming them with the competitive skills and abilities to deal with future demands, and fostering and improving their critical thinking and creative thinking and problem solving skills so as to underpin the process of becoming a learning organization.

Linked to the above, the findings of this research corroborate the results of other empirical research; for instance, according to Dulewicz and Higgs (2005) empowering is characterised by the following behaviours: "Gives staff autonomy, encourages them to take on personally challenging demanding tasks. Encourages them to solve problems, produce innovative ideas and proposals and develop their vision and a broader vision. Encourages a critical faculty and a broad perspective." In addition, according to Watkins and Marsick (2003) empowering people toward a collective vision is characterised by situations where "Responsibility is distributed close to decision making, so that people are motivated to learn toward what they are held accountable to do".

Thus, "everyone in the organization has an idea of what the whole picture looks like, knows how to get something done, has a budget with which to take action, and has knowledge of how to influence others. In this case, each worker has access to information about how to plan learning and how to assess their needs in relation to the needs of the organization" (Mababu and Revilla, 2016, p.2432)

\subsection{Achieving for Connecting the Organization to Its Environment}

Another leadership competency identified by the participants was that academics and researchers as leaders in the NUB should have the achieving skills to enthusiastically connect the organization to its environment. Achieving such connections has been identified as a leadership competency by a number of writers in the literature and is characterised by "Unwavering determination to achieve objectives and implement decisions" (Müller and Turner, 2010, p. 21) and being "Willing to make decisions involving significant risk to gain an advantage. Decisions are based on core business issues and their likely impact on success. Selects and exploits activities that result in the greatest benefits to the organisation and its performance" Dulewicz and Higgs (2005, p.111), The participants in this study emphasised the critical role of their skill in taking risks, for example in exploiting the opportunities of national conferences and governmental support to obtain innovative knowledge and ideas in their organization, and collaborating with their colleagues and counterparts in other faculties and for the greatest benefit of their NUB, as illustrated in the following excerpts.

"As a faculty of mass communication, we collaborate with other faculties in the university: for instance, we have participated in the national conference for youth under sponsorship of the president of the Egypt, so we selected students from all the NUB faculties to represent our university in the conference; then, they returned back with new information and knowledge" (AA)

"I have both academic and professional experience; now the trend of the Egyptian government and the world shifted towards enterprise education, as such I sent the faculty members, students and staff to practical and empirical visits to the stock market, factories, banks, financial organizations so as to get knowledge and information from real experience." (AM)

"We also send our students of the faculty of pharmacy to learn mathematics and statistics, pharmaceutical marketing 
modules from the faculty of Marketing and Business Administration, and to the faculty of Mass Communication to study modules such as pharmaceutical advertising." (HM)

"We are running in the faculty of pharmacy some courses for training for new candidates, apprentices and external professionals in our factory unit of medicine in our university, I sell well-bred animals according to the international standards and research to laboratories, locals, and professionals; this actually brings additional income to our University." (HM)

The findings of this research reflect Watkins and Marsick's (2003) characterization: "People are helped to see the effect of their work on the entire enterprise; people scan the environment and use information to adjust work practices; the organization is linked to its communities" (ibid., p. 139). This quote from Watkins and Marsick also appears to summarise the understanding of the learning organisation process exhibited by many interviewees, who felt that achieving competency is critical to support the process of being a learning organization by connecting the NUB to the internal and external environment by creating a milieu of interdependencies with other faculties to achieve the educational and learning needs of the student, and also by following the Egyptian government's policy of implanting enterprise-centred education, for example, by offering training courses for external professionals and breeding superior breeds of animals to sell to the local community. The findings of this research confirm those from other empirical studies, for example, the following behaviours and actions: "Connect the Organization to its Community and Environment: Interdependencies between the organization and its internal and external environment are acknowledged and worked through. The connection between individual and organization in terms of the internal environment should be responsive to members of the organization and their work-life needs. External customers in the broadest sense include the earth, our society, and the communities in which the organization resides" (Mababu and Revilla, 2016, p.2432).

It can be argued that achieving connection to the organization's environment as a leadership competency supported the academics and researchers in this study to achieve the learning process and bring about change in their university by creating a reciprocity of benefits between the NUB and its environment. Thus, as Voolaid and Ehrlich (2017, p. 342 ) point out, it is "extremely important for a university to feel itself as part of the community."

\subsection{Influence for Providing Strategic Leadership for Learning}

Another leadership competency identified by the interviewees as a crucial skill for supporting the process of becoming learning organization was that leaders should have the strategic leadership skills to manage change by influencing their subordinates, colleagues and students. This is in line with the findings and conclusions widely reported in the literature.

According to Watkins and Marsick (2003), the seventh criterion of the DLOQ framework for Dimensions of the Learning Organization Questionnaire is to "Provide strategic leadership for learning," characterised as occurring when "Leaders model, champion, and support learning; leadership uses learning strategically for business results" (ibid. p.139). According to Rowe (2001), "Strategic leadership is the ability to influence others to voluntarily make day-to-day decisions that enhance the long-term viability of the organization, while at the same time maintaining its short-term financial stability" (Rowe, 2001, p.81-82). Influence as a leadership competency has been described as "the influencing process between leaders and followers to achieve organizational objectives through change" (Lussier and Achua, 2013, p.5), which involves "intentionally influencing and motivating team members with a view to achieving goals" (Kuster et.al., 2011, pp.214-215).

The participants agreed that the ability to influence the relationship between leaders, in this case academics and researchers, and their students appeared to be a critical competency for them to manage change and should be regarded as an essential part of the leader's task. The quotes below present robust support for the opinion that leaders in the NUB should be able to manage change by influencing others, to provide strategic leadership for learning in terms of being able to listen, deal with conflict and paradox and provide a rationale for change.

"Communication, monitoring, self-confidence, and listening are the prerequisite skills for me. I have an open door policy for my staff and students. I do open meetings to discuss conflicts, problems that may arise, write them down, conduct another meeting to know the source of these problems with my staff, analyse it, and take the most appropriate decision or resolution. I do my best to solve it or give my recommendations to be addressed." (AA)

"Good communication, listening with both the higher administration of the NUB and my colleagues, students, and staff, monitoring even trivial things in my faculty, getting people on the right track from deviation so as to reach our optimal goal; thus support the learning flow in my faculty." (NS)

"I have an open door policy for students and staff. When a student comes in, he/she will get a sense of commitment, 
trust, we listen to their problems, we encourage them to conduct research with their peers, socialize with farmers and locals to get the knowledge they require for their research; I can smell their feelings, desire for work and creativity; based on these characteristics I select some of them for heavy projects." (HM)

"We are aiming to encourage and improve our students' critical thinking and creative thinking, problem solving skills." (AM)

The behaviours described in the above quotes also appear to shape the role of academics and researchers of the NUB toward supporting the process of the learning organisation model as proposed by Watkins and Marsick (2003) and offer evidence that the NUB is a learning organisation. The findings of this research agree with what is stressed by other empirical studies. For instance, Influence Competency, as defined by Dulewicz and Higgs (2005), involves persuading others to "change views based on an understanding of their position and a recognition of the need to listen to this perspective and provide a rationale for change" (ibid., p.112). Influencing people seemed to contribute significantly in creating this learning environment where academics and researchers listen, motivate, analyse problems and provide rational solutions to their colleagues and students in order to encourage them to generate new ideas and allow learning to prevail. Interviewees in the current study identified Influencing as another critical leadership skill, which helped them to support the learning organization process in terms of listening, encouraging their students and colleagues to scan the environment to acquire the relevant knowledge to support their research, socialise with their peers, interact with locals and farmers for knowledge sharing and encourage and improve their students' critical and creative thinking, and problem solving skills, to achieve a learning organization.

\subsection{Selecting for Financial Performance as a Result of Learning Organization}

It has been argued that being a learning organization is the determinant for achieving competitive advantage, which directly ensures optimal financial performance (Jiang and Li, 2008). According to Watkins and Marsick (2003, p. 136) financial performance is a "state of financial health and resources available for growth", while Li et al. (2008) posit that the financial performance of any organization can be assessed qualitatively by asking questions about efficiency, growth, and profits.

The academics and researchers of the NUB believed that their skills to achieve in selecting and executing activities and opportunities that had the greatest benefits for their organisation were important. The participants also explained that the connected system and infrastructure of the NUB website and networking media enabled them to train newly-appointed candidates and apprentices, connect with their surrounding environment, sell the livestock they bred to the community for additional income, as well as reducing tuition fees to attract more students in order to compete in the private education market. Consequently, it can be seen how these "learning and development activities in organizations enhance knowledge performance and ultimately contribute to obtaining financial outcomes" (Kim et al., 2017, p.186), as illustrated in the following excerpts.

'We are running some courses for training for new candidates, apprentices and external professionals in our factory unit of medicine in NUB university, I sell well-bred animals according to the international standards and research to laboratories, locals, and professional this actually bring additional income to our university. As such, we are getting more and more students studying pharmacy every year till we attracted 2500 students' (HM)

"The university has a lucrative policy which is to reduce the submission fees, application fees, and affording free foundation for new students, and declare on its website for scholarships for excellent students, so as to attract as much students as it can, thus achieve learning and additional income simultaneously." (FR)

"Based on our planning and learning strategies, we have succeeded in increasing the amount of the applicants to the school of business administration; this because we do foundation courses for free for business students, free English courses, reduce their fees, do some scholarships as well, so loads of applicants are rushing every year to join us; thus we teach them, spread learning, and increase the NUB income," (AG)

The findings of the current research concur with the conclusions of other authors such as Watkins and Marsick (2003), who state that in a learning organization, the efforts to achieve financial results "clearly must be supported by organizational systems to both capture learning and scan the environment" (ibid., p. 142). Furthermore, as stressed in the above quotes from the interviewees, system connection, which was related to 'Achieve' as a leadership competency was recognized as a key determinant in aiding academics and researchers to scan the environment and utilise opportunities to obtain financial results. This also matches the characterization by Dulewicz and Higgs (2005) that the leader who possesses Achieving as a leadership competency 'Selects and exploits activities that result in the greatest benefits to the organisation and its performance' (ibid., p.111)

Other empirical contributions emphasise the link between system connection (the $6^{\text {th }}$ condition of the $\left.7 \mathrm{Cs}\right)(\mathrm{O}$ 'Brien 
1992, Watkins and Marsick, 2003) and financial performance. Yang et al., (2004, p.49) reported that: "Although provide leadership for learning was the only variable that had direct influence on financial performance, system connection affected financial performance indirectly." Indeed, learning is considered a cornerstone for triggering financial performance (Kaplan and Norton, 1992, Kim and Watkins, 2017).

\subsection{Strategic Leadership for Utilising Knowledge Performance}

It has been argued that the way a learning organization enables an organization to become more effective is by enhancing the organization's knowledge and financial performance (Kim et al., 2017, p. 178). Marsick and Watkins (2003) define knowledge performance as "the creation and enhancement of products and services because of learning and knowledge capacity (lead indicators of intellectual capital" (ibid., p. 139).

, as illustrated in these comments. "With our paperless, digital system enabled us to execute multitasks online, such as signing leave permission to staff, students and colleagues, creating, acquiring, and sharing information with the NUB staff, students and colleagues plus getting students'feedback on assignments, dissertations, and projects, as well as staff affairs, and in turn, utilise this information by giving them my comments, corrections, reviews to amend, and improve their work, so that we can reduce human resources involved, save money, time and office hours." (AA)

"We have an outreach system so as students can teach their colleagues in terms of their assignments, presentations, study intuitions, etc. thus at the end of the day we learn from each other" (NS)

The above excerpts support Marsick and Watkins' (2003) conclusion that a system to capture and disseminate acquired and created knowledge has to be in place as a prerequisite for a learning organization. In fact, they found that "the only direct predictor of knowledge performance is whether the organization has created systems to capture and share knowledge" (ibid., p. 140). Similarly, Kim et al. (2017) found that "a learning organization is a significant determinant of knowledge performance" (ibid., p.185).

Watkins and Marsick (2003, p. 273) posited that "Knowledge is the key asset base from which to predict earnings." Increasingly, it has been argued that knowledge performance is considered to be a "significant latent indicator of future financial performance" (Johnson and Kaplan, 1987; Wilcox and Zeithaml, 2003). Moreover, it has been found that a "learning organization has a positive effect on knowledge performance; knowledge performance has a positive effect on financial performance" (Kim et al., 2017, p.177). This quote from one of the interviewees illustrates this dual benefit:

"Based on our planning and learning strategies, we have succeeded in increasing the amount of the applicants to the school of business administration, this because we do foundation courses for free for business students, free English course, reduce their fees, some scholarships as well; therefore, we have loads of applicants are rushing every year to join us; thus we teach them, spread learning, and increase the NUB income" (AG)

However, "having the knowledge assets does not guarantee that the company will know how best to use them" (Marsick and Watkins, 1999, p. 79). In line with this quote, the authors indicated that there is a correlation between knowledge and financial performance without stating what are the abilities and skills needed to utilise knowledge to generate a financial outcome. The answer comes from Watkins and Kim, 2018), who observed that "System-level dimensions, such as system connections or strategic leadership for learning, consistently show higher correlations with organizational performance than individual or team dimensions, especially knowledge performance" (ibid., p.21) In line with this finding, the interviewees also emphasised the fact that their strategic leadership skills enabled them to foresee future opportunity and plan prospective strategies for raising financial income of the NUB by improving the knowledge performance

Serfontien and Hough, (2011) define strategic leadership, is an ability by the leader to anticipate, prepare and position for the future leaders are supposed to possess the skill to expect, create a vision, encourage others and practise flexibility, to generate a strategic and viable future of the organization (Kleijnen, et.al., 2009).

According to the participants' comments above, their strategic leadership competencies enabled them to plan strategically, for example, how to attract more applicants to the business school via implementing strategic learning in the NUB. Consequently, there is a definite relationship amongst the leadership's characteristics, an organization's strategies and its performance (Ireland and Hitt 2002). This corroborates the finding reported by Kim et al. (2017) that "performance, which is significantly impacted by a learning organization, fully mediates the relationship between a learning organization and financial performance" (ibid., p.186).

\section{Conclusion and Discussion}

The significance of leadership in generating the circumstances and structures characteristic of a learning organisation, 
and in overcoming prospective barriers has been addressed widely (Watkins and Marsick 1996, Popper and Lipshitz, 2000). In this study, Watkins and Marsick's DLOQ was used qualitatively, "To learn how university staff perceive their university as a learning organization," as recommended by Voolaid and Ehrlich (2017, p. 343). Leadership competencies emerged as a new moderator acting as complementary component of the DLOQ framework in supporting academics and researchers make the Al Nahda University a learning organization, leading through knowledge performance to effective financial performance in the case of the NUB, as illustrated in Figure 1 below. These findings indicate that leadership skills are not only acting as a backbone supporting the 7Cs (Seven Characteristics) in the DLOQ framework proposed by (Watkins and Marsick, 2003), but also support knowledge performance for effective financial performance. Becoming a learning organization emerged as a by-product of the leadership competencies that underpin the seven dimensions of learning at individual, team and organisational level, plus the two key results obtained by Watkins and Marsick (2003), and knowledge performance has to be underpinned by strategic leadership competency, which affects the financial performance that is underpinned by selecting competency in a complementary framework of learning organization, as in the case of the NUB in Egypt. However, this contradicts the findings of Kim et al., (2017, p.177) that "learning organization has a positive effect on knowledge performance; knowledge performance has a positive effect on financial performance; and knowledge performance fully mediates the relationship between a learning organization and financial performance." Thus, the 7Cs proposed by Watkins and Marsick (2003) do not lead to a learning organization; nor does being a learning organization by itself lead to knowledge performance and financial outcomes unless fully supported by leadership competencies, as has been confirmed in the case of the Al-Nahda University operating in Egypt.

As presented in Figure 1, at the backbone of the framework for the LO are the nine leadership competencies that underpin the seven dimensions of the DLOQ, in addition to the two results for learning. Thus, the underlying roles of a leader can be seen as that of "a sculptor" of the LO (Watkins and Marsick, 1993, p. 174). who plays the pivotal role of "empowering people with a vision and engaging in a dialogue that shapes the emerging product" (ibid., p.95)., a leader plays the pivotal role by empowering people with a vision and engaging in a dialogue that shapes the emerging product" (ibid., p.95). This accentuates the role of leadership competencies in the learning organization and led to its insertion into the DLOQ framework as a complementary part, which is considered as the major finding of this research. 


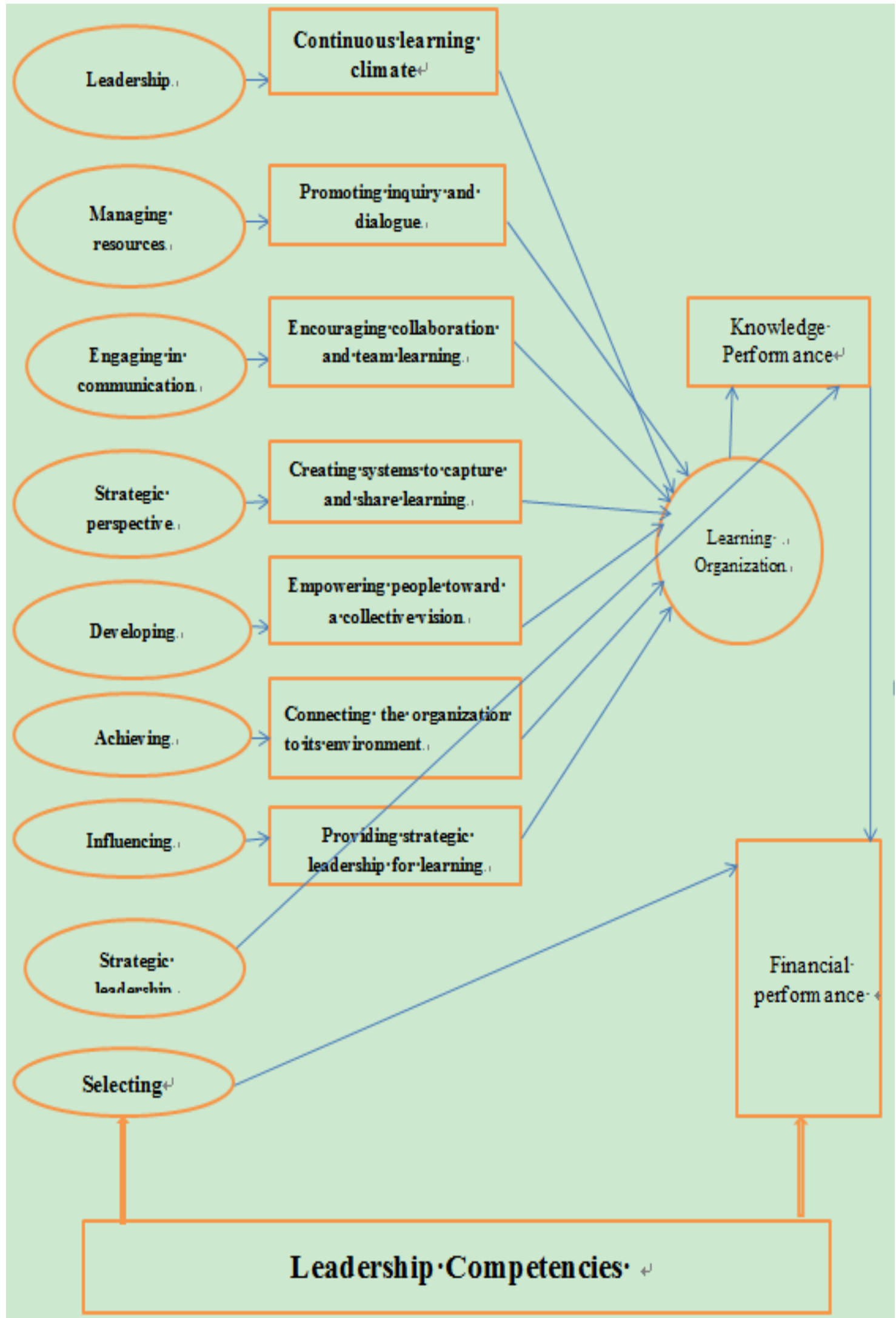

Figure 1. Leadership competencies as new determinants for $\mathrm{LO}$ and results 
On the basis of views voiced by executive academics and researchers' staff of the NUB, it can be said that the Al-Nahda University in Egypt is considered a learning organization because it has addressed learning levels (individual, group, and organization) of the DLOQ dimensions' plus the knowledge and financial results. Potential drivers for that were possibly that the NUB personnel possess the leadership competencies that were inserted into the DLOQ framework, as shown in Figure1 above. The research results also confirm the definition of Garvin (1993) that a learning organization is "an organization skilled at creating, acquiring, and transferring knowledge, and at modifying its behaviour to reflect new knowledge and insight" (ibid., p. 80). In addition, it appeared that the NUB created conditions for learning and utilised this learning for the benefit of its environmental needs. This supports the view of Stoll and Kools (2017) that the LO is an organisation that creates encouraging circumstances for learning and makes use of its own learning to adapt to the environment.

Moreover, the reports of the respondents in the current study refute what has been claimed in recent literature regarding dialogue and teamwork, for example the dialogue and the teamwork dimensions of the DLOQ are weak in a university, because "teaching is personal and collaboration with other teachers and disciplines not always necessary" (Voolaid and Ehrlich, 2017.p. 351). In contrast, according to the current research, managing resources and engaging in communication as leadership competencies enabled academics and researchers of the NUB to innovate and open discussion for creating knowledge and new ideas.

Furthermore, on the basis of interviewees responses it can be seen that their possession of a strategic perspective as a leadership competency enabled them to deal with their system to capture and share knowledge among their colleagues, staff, and students from a wider perspective, and explore a wide range of relationships that allow flexibilities by exploiting a main system like the ELS and minor systems like Facebook and WhatsApp. This also contradicts assertions in the literature that HEIs are structurally inflexible and strict organizations, and that this constitutes an obstacle toward becoming learning organizations (White and Weathersby, 2005; Örtenblad, 2010).

Moreover, on the information collected of the interviews clearly shows that developing as a leadership competency enabled academics and researchers the Al Nahda university to be aware of their organization's mission and vision and that everyone had an idea of what the whole picture looked like in the NUB and were able to share their visions and perspectives with each other. This also contradicts other empirical research (Senge, 1990; Starkey, 1996), which concluded that "not all employees have a common understanding of the university's mission and work objectives" (Voolaid and Ehrlich, 2017, p. 342).

Achieving was also another leadership competency that enabled academics and researchers to use information to adjust their work practices and decide to embark on activities that link the NUB with its communities. This concurs with opinions of Baldridge (1983), Lorange (1997) and (Voolaid and Ehrlich, 2017) regarding the importance of a university to perceiving itself as part of the local community.

Influence was another critical leadership competency that emerged to enable academics and researchers of the NUB to support the process of learning by encouraging their colleagues, staff and students to scan the environment for knowledge acquisition, do extra research, attend workshops, and conferences for the and listening to them to provide them with guidance and tuition and also provide strategic leadership for learning. This confirms findings by other scholars (e.g., Senge, 1996; White and Weathersby, 2005; Voolaid and Ehrlich, 2017)

Strategic leadership competency also emerged as a crucial aid to learning: interviewees foresaw future opportunities, planned strategically for learning and knowledge performance and dealing with conflicts and provide a rationale for change. Strategic leadership competency is well-covered in the current literature (Kim et al., 2017; Watkins and Kim, 2018), as it relates to positive knowledge performance that results in good financial performance.

A number of informative comments were given by interviewees on how leaders created a learning environment by selecting activities that would lead to positive financial outcomes to the NUB. Having knowledge was cited as insufficient for achieving financial results unless the organizations "know how best to use" that knowledge (Marsick and Watkins, 1999, p. 79). Thus, Selecting as a leadership competency was identified as an additional significant leadership skill that helped academics and researchers of the NUB for achieving financial performance.

Thus, through the case of the Al Nahda University in Egypt, the research illuminated the indispensable role of leadership competencies, and the HEIs' desire to become learning organizations, which supports the application of the DLOQ framework.... It also clearly identified the Al Nahda University as a learning organization.

\section{Implications and Limitations}

This research contributes to the illumination of leadership competencies as an unexplored dimension of the theoretical framework of a learning organization proposed by Watkins and Marsick $(1993,1996)$, in addition to the 
two competencies that support the knowledge and financial performance of the learning organization. Moreover, all the items were analysed at individual, group, and organizational levels, and the results showed that by examining the seven dimensions of a learning organization through a qualitative approach, different results were obtained from those of previous empirical studies which used the DLOQ. The findings of this research contribute to a better understanding of which leadership competencies can support the process of becoming a learning organization, as illustrated by the case of the NUB.

Practically, this research emphasises the need for HEIs to become learning organizations, particularly by identifying which competencies are needed to achieve their optimal performance. The current literature has already identified the path that can be followed by organizations that want to become a learning organization, but unlike the current research, these prior studies did not illuminate the areas that require competent leadership skills to support the process of becoming a learning organization.

Consequently, it cannot be overemphasised that, for HEIs which want to become learning organizations, leadership competencies have to be nurtured developed and promoted in a strategic way. This research also highlights the challenging task for the HRM department in selecting, recruiting, training and developing applicants with leadership competencies so as to be able to deal with the challenges faced in becoming a learning organization.

The limitations of this research are a basis to propose future research guidelines. For instance, this research analysed primary data using the DLOQ, in a qualitative method from only one of the HEIs in Egypt. Future research should further investigate the results obtained in this study by analysing data collected using different research methods in different contexts and with different samples.

Although this research and its analysis raise substantial concerns regarding the qualitative reframing of the DLOQ, an unexplored chain of competencies has been revealed as a complementary component of the DLOQ, which can also extend our understanding of the perceptions of academics and researchers regarding the learning organization process. This relates to "concerns about the ability to perceive and evaluate performance at the organizational level for people not in managerial positions" (Watkins and Kim, 2018, p.21). Thus, investigating the perceptions of organization members is also recommended for future research as urged by Mababu and Revilla, 2016 who also recommend analysing the effect of perception of faculty members on the dimensions of a learning organization. This aspect might be incorporated into the DLOQ in future research.

\section{References}

Afshari, M., Shahhosseini, A., Kosaripoor, M., \& Molajafari, S. (2013). The role of managerial skills in developing characteristics of learning organization in physical education organization. International Journal of Sport Studies, 3(4), 398-405.

Alavi, M., \& Leidner, D.E. (2001). Review: knowledge management and knowledge management systems: conceptual foundations and research issues. MIS Quarterly, 25(1), 107-136. https://doi.org/10.2307/3250961

Bess, J., \& Dee, J. (2008). Understanding college and university organization: Theories for effective policy and practice, volume II: Dynamics of the system. Sterling, VA: Stylus Press.

Birdthistle, N. (2006). Small family businesses as learning organisations: an Irish study. PhD thesis, University of Limerick, Limerick.

Borden, V., \& Kezar, A. (2012). Institutional research and collaborative organizational learning. In Howard, R., McLaughlin, G., \& Knight, W. (Eds.), The Handbook of Institutional Research (pp. 86-106). Jossey-Bass, San Francisco, CA.

Bresó, I., Gracia, F.J., Latorre, F., \& Peiró, J.M. (2008). Development and validation of the team learning questionnaire. Comportamento Organizacional e Gestão, 14(2), 145-160.

Chrispen, Ch., \& Mukeredz, T.G. (2013). Learning Organisation Concepts in Open and Distance Learning University: Their Application in Fluid Times of Discontinuity and Uncertaint. Journal of Social Changes, Interdisciplinary Reflection of Contemporary Society, 36(1), 29-40. https://doi.org/10.1080/09718923.2013.11893170

Dee, J., \& Leisyte, L. (2017). Knowledge sharing and organizational change in higher education. The Learning Organization, 24(5), 355-365. https://doi.org/10.1108/TLO-04-2017-0034

DeVellis, R.F. (2003). Scale Development: Theory and Applications (2nd ed.). Sage Publications, Newbury Park, CA.

Dobák, M., \& Antal, Z. (2010). Vezetés és szervezés. Budapest: Aula. 
Dulewicz, V., \& Higgs, M. (2005). Assessing leadership styles and organisational context. Journal of Managerial Psychology, 20(2), 105-123.

Ferincz, A. (2016). Adaptation and change in organizational learning research. Vezetéstudomány/Budapest Management Review, 47(5), 53-63.

Gakenia, C., Katuse, P., \& Kiriri, P. (2017). Influence of Strategic Leadership Style on Academic Performance of National Schools in Kenya. IOSR Journal of Business and Management, 19(7),9-24.

Garvin, D. (1993). Building a learning organization. Harvard Business Review, 7(4), 78-84.

Garvin, D.A., Edmondson, A.C., \& Gino, F. (2008). Is yours a learning organization? Harvard Business Review, 86(3), 109-116.

Gentle, P., \& Clifton, L. (2017). How does leadership development help universities become learning organizations?. The Learning Organization, 24(5).

Gido, J., \& Clements, J. (1999). Successful Project Management. South-Western Collage Publishing.

Harris, A., \& Jones, M. (2018). Leading schools as learning organizations. School Leadership \& Management, 38(4), 351-354. https://doi.org/10.1080/13632434.2018.1483553

Hitt, L., Wu, D., \& Zhou, X. (2002). Investment in Enterprise resource planning: Business Impact and productivity measures. Journal of Management Information https://doi.org/10.1080/07421222.2002.11045716

Hitt, M.A., \& Ireland, R.D. (2002). The essence of strategic leadership: Managing human and social capital. Journal of Leadership \& Organizational Studies, 9(1), 3-14. https://doi.org/10.1177/107179190200900101

Holyoke, L.B., Sturko, P.A., Wood, N.B., \& Wu, L.J. (2012). Are academic departments perceived as learning organizations? Educational Management Administration \& Leadership, 40(4), 436-448. https://doi.org/10.1177/1741143212438219

Jackson, S.E., \& Schuler, R.S. (2002). Managing individual performance: A strategic perspective. Psychological Management of Individual Performance, 372-390.

Jiang, X., \& Li, Y. (2008). The relationship between organizational learning and firms' financial performance in strategic alliances: A contingency approach. Journal of World Business, 43(3), 365-379. https://doi.org/10.1016/j.jwb.2007.11.003

Johnson, H.T., \& Kaplan, R.S. (1987). Relevance Lost-the Rise and Fall of Management Accounting. Harvard Press, Boston, MA.

Jyothibabu, C., Farooq, A., \& Bhusan Pradhan, B. (2010). An integrated scale for measuring an organizational learning system. The Learning Organization, 17(4), 303-327. https://doi.org/10.1108/09696471011043081

Kaplan, R.S., \& Norton, D.P. (2004). Strategy Maps: Converting Intangible Assets into Tangible Outcomes. Harvard Business School Press, Boston, MA.

Kezar, A. (2005). What campuses need to know about organizational learning and the learning organization. In A. Kezar (Ed.), Organizational learning in higher education (New directions for higher education (No. 131, pp. 7-22). San Francisco: Jossey-Bass. https://doi.org/10.1002/he.183

Kezar, A., \& Elrod, S. (2012). Facilitating interdisciplinary learning: Lessons from project Kaleidoscope. Change, 44(1), 16-25. https://doi.org/10.1080/00091383.2012.635999

Kim, J., Egan, T., \& Tolson, H. (2015). Examining the dimensions of the learning organization questionnaire: a review and critique of research utilizing the DLOQ. Human Resource Development Review, 14(1), 91-112. https://doi.org/10.1177/1534484314555402

Kim, K., Watkins, K.E., \& Lu, Z. (2017). The impact of a learning organization on performance: Focusing on knowledge performance and financial performance. European Journal of Training and Development, 41(2), 177-193. https://doi.org/10.1108/EJTD-01-2016-0003

Kleijnen, J.D. (2009). Organisational values in higher education: Perceptions and preferences of staff. Quality in Higher Education, 15(3), 233-249. https://doi.org/10.1080/13538320903343123

Kuster, J., Huber, E., Lippmann, R., Schmid, A., Schneider, E., Witschi, U., \& Wüst, R. (2011). Project Management Handbook. Springer. 
Li, H., Meng, L., Wang, Q., \& Zhou, L. (2008). Political connections, financing and firm performance: Evidence from Chinese private firms. Journal of Development Economics, 87(2), 283-299. https://doi.org/10.1016/j.jdeveco.2007.03.001

Lussier, R., \& Achua, C. (2013). Leadership: theory, application \& skill development. Cengage Learning.

Mababu, R.M., \& Revilla, R.G. (2016). Determinants of Learning Organization in Higher Education. 10th International Technology, Education and Development Conference.

Mahseredjian, A., Karkoulian, S., \& Messarra, L. (2011). Leadership styles correlate of learning organization in a non-western culture. The Business Review, Cambridge, 17, 269-277.

Miles, M., \& Huberman, A. (1994). Qualitative Data Analysis: An Expanded Sourcebook. Sage, Beverly Hills, CA.

Müller, R., \& Turner, R. (2010). Project-Oriented Leadership. Gower Publishing Limited.

Nonaka, I. (1991). The knowledge creating company. Harvard Business Review, 69(6), 96-104.

O’Brien, M.J. (1992). The learning organization profile (version B). Milford, OH: O’Brien Learning Systems.

Ortenblad, A. (2002). Organizational learning: A radical perspective. International Journal of Management Reviews, 4(1), 87-100. https://doi.org/10.1111/1468-2370.00078

Örtenblad, A. (2010). The learning organisation: a universally-applicable concept or an ambiguous basis in need of local interpretation? (guest editorial). International Journal of Learning and Change, 4(1), 1-6.

Örtenblad, A. (2018). What does "learning organization" mean? The Learning Organization, 25(3), 150-158. https://doi.org/10.1108/TLO-02-2018-0016

Patterson, G. (1999). The learning university. The Learning Organization, 6(1), 9-17. https://doi.org/10.1108/09696479910255675

Poonam, V.R., \& Jennifer, R. (2017). Knowledge management in higher education institutions: enablers and barriers in Mauritius. The Learning Organization, 24(5), 366-377. https://doi.org/10.1108/TLO-03-2017-0030

Popper, M., \& Lipshitz, R. (2000). Installing mechanisms and instilling values: the role of leaders in organizational learning. The Learning Organization, 7(3), 135-144. https://doi.org/10.1108/09696470010335854

Prelipcean, G., \& Bejinaru, R. (2016). Universities as learning organisations in the knowledge economy. Management Dynamics in the Knowledge Economy, 4(4), 469-492.

Reese, S. (2017). Is the higher education institution a learning organization (or can it become one)?. The Learning Organization, 24(5), 378-380. https://doi.org/10.1108/TLO-05-2017-0041

Rowe. (2001). Creating Wealth in Organizations: The Role of Strategic leadership. The Academy of Management Executives, 15(1), 81-95. https://doi.org/10.5465/ame.2001.4251395

Senge, P. (1990). The fifth discipline: The art and practice of the learning organization. New York: Doubleday/Currency.

Senge, P., Kleiner, A., Roberts, C., Ross, R., Roth, G., \& Smith, B. (2014). The Dance of Change. The Challenges to Sustaining the Momentum in Learning Organizations. New York: Doubleday.

Senge, P.M. (1999, November). Learning Leaders. Executive Excellence, 12-13.

Senge, P.M. (2006). The Fifth Discipline - The Art and Practice of the Learning Organization (Revised ed.). New York, NY: Doubleday Dell.

Serfontien, K., \& Hough, J. (2011). Nature of the Relationship Between Strategic Leadership Operational Strategy and Organizational Performance. Sajems Ns, 14, 393-405. https://doi.org/10.4102/sajems.v14i4.21

Shafiei, A., \& Fard, A.N. (2015). Investigating the effect of management skills on the level of strategic thinking of the managers of Kashan Municipality.

Starkey, K. (1996). Introduction. In Starkey, K. (Ed.), How Organizations Learn. International Thomson Business Press, London.

Stoll, L., \& Kools, A. (2017). The school as learning organisation: a review revisiting and extending a timely concept. Journal of Professional Capital and Community, 2(1), 2-17. https://doi.org/10.1108/JPCC-09-2016-0022

Strandli, P.I. (2006). The university: a learning organization?. An Illuminative Review Based on System Theory, Karlstad University Studies No. 23, Karlstad University Press, Karlstad. 
Voolaid, K., \& Ehrlich, Ü. (2017). Organizational learning of higher education institutions: the case of Estonia. The Learning Organization, 24(5), 340-354. https://doi.org/10.1108/TLO-02-2017-0013

Watkins, K.E., \& Dirani, K.M. (2013). A meta-analysis of the dimensions of a Learning Organization Questionnaire looking across cultures, ranks, and industries. Advances in Developing Human Resources, 15, 148-162. https://doi.org/10.1177/1523422313475991

Watkins, K.E., \& Kim, K. (2018). Current status and promising directions for research on the learning organization. Human Resource Development Quarterly, 29(1), 15-29. https://doi.org/10.1002/hrdq.21293

Watkins, K.E., \& Marsick, V.J. (1993). Sculpting the Learning Organization: Lesson in the Art and Science of Systemic Change. San Francisco, CA: Jossey-Bass.

Watkins, K.E., \& Marsick, V.J. (1996). In Action: Creating the Learning Organization. Alexandria, VA: American Society for Training and Development.

Watkins, K.E., \& Marsick, V.J. (2003). Demonstrating the value of an organization's learning culture: the dimensions of the learning organization questionnaire. Advances in Developing Human Resources, 5(1), 132-151.

White, J., \& Weathersby, R. (2005). Can universities become true learning organizations?. The Learning Organization, 12(3), 292-298. https://doi.org/10.1108/09696470510592539

Wilcox, K.A., \& Zeithaml, C.P. (2003). Measuring organizational knowledge: a conceptual and methodological framework. Strategic Management Journal, 24(8), 763-772. https://doi.org/10.1002/smj.333

Yang, B., Watkins, K.E., \& Marsick, V.J. (2004). The construct of the learning organization: Dimensions, measurement, and validation. Human Resource Development Quarterly, 15(1), 31-55. https://doi.org/10.1002/hrdq.1086

Zenger, J., \& Folkman, J. (2002). The extraordinary leader. New York: McGraw-Hill. 